\title{
Controle integrado de espécies de Simulium (Diptera, Simuliidae) por Bacillus thuringiensis e manejos mecânicos no riacho e nos vertedouros de tanques de piscicultura, Almirante Tamandaré, Paraná, Brasil
}

\author{
Fabiane Petry ${ }^{1}$, Ana Leuch Lozovei ${ }^{1}$, Maria Elizabeth Ferraz ${ }^{2} \&$ Luiz Gonzaga dos Santos Neto ${ }^{1}$
}

${ }^{1}$ Departamento de Patologia Básica, Setor de Ciências Biológicas, Universidade Federal do Paraná. Caixa Postal 19031, 81531-990 Curitiba-PR, Brasil. Endereço eletrônico: fflinper@bol.com.br

${ }^{2}$ Centro de Saúde Ambiental, Torre A, Mesanino, Prefeitura Municipal de Curitiba. Av. João Gualberto 623, 80030-000 Curitiba-PR, Brasil.

\begin{abstract}
Aвstract. Integrated pest control of Simulium (Diptera, Simuliidae) with Bacillus thuringiensis and mechanical handling in creek and pisciculture spillway, Almirante Tamandaré, Paraná, Brazil. At Riacho dos Padres, Chácara Evíssima, a small agribusiness venture featuring fish, poultry and cattle farming; a recreation outdoor facility and Event Hall, ubicated in Curitiba's Metropolitan Area, simuliid populations boast high proliferation rates, delivering serious impact to local people with their noxious bites, to such an extent as to impair the daily meetings of people. From January to August 2002, 24,021 pupae were collected from which the following species and respective frequencies were identified: Simulium inaequale $(55.24 \%)$, Simulium perflavum $(16.81 \%)$, Simulium pertinax $(13.93 \%)$, Simulium orbitale $(8.03 \%)$, Simulium subnigrum $(4.92 \%)$, Simulium distinctum $(1.03 \%)$ and Simulium incrustatum $(0.04 \%)$. Local pest control measures were carried out from the February 28 to August 8, 2002. Main integrated pest control measures taken consisted in the application of biopesticide Bacillus thuringiensis israelensis (Bti) and mechanical handling, not only by removing the immatures (eggs, larvae and pupae) by means of drain brushing, but also by removing natural and artificial substrates from the bed. Larval mean density, monitored at artificial polythene strips substrates (area $13,500 \mathrm{~cm}^{2}$ ), averaged 6.7 and 11.5 larvae $/ \mathrm{cm}^{2}$ before the application of $\mathrm{Bti}$ at the creek bed extension $75 \mathrm{~m}$ and on the dam spillway, respectively. Larval mass reduction at creek bed and at the spillway with application of Bti from 1.77 to $2.09 \mathrm{mg} / \mathrm{litre}$ of active ingredient for one minute exposure time and means of mechanical handlings monitored at polythene strips substrates (area $20,250 \mathrm{~cm}^{2}$ ) varied, respectively from $72.61 \%$ to $99.97 \%$ and from $74.91 \%$ to 99.45 with outflows from 0.39 to 0.45 and from 0.38 to $0.43 \mathrm{~m}^{3} /$ minute. At the one of the dam spillways with area of $5,110 \mathrm{~cm}^{2}$, average larval density in the first mechanic handling was 10.27 larvae $/ \mathrm{cm}^{2}$. However, at this spillway, larval reduction by means of mechanical handlings was from $53.81 \%$ to $99.59 \%$. Integrated pest control did down sized the number of bytes to the level wished, thus obtaining the positive effect aimed.
\end{abstract}

KEYwords. Control Bti; mechanical handling; creek; pisciculture spillway dam; Simuliidae.

Resumo. No Riacho dos Padres na Chácara Evíssima, numa microempresa de agronegócio com criação de peixes e animais domésticos, área de lazer e salão de eventos, localizada na Região Metropolitana de Curitiba, os simulídeos em grande proliferação causaram sério impacto com as picadas a tal ponto que dificultaram o convívio habitual. De janeiro a agosto de 2002, coletou-se 24.021 pupas por meio das quais foram identificadas as espécies: Simulium inaequale, Simulium perflavum, Simulium pertinax com $85,98 \%$ e Simulium orbitale, Simulium subnigrum, Simulium distinctum e Simulium incrustatum com somente $14,02 \%$ de freqüência. O combate a estas populações iniciado em 28 de fevereiro terminou em 08 de agosto de 2002. O controle integrado consistiu na aplicação de biopesticida Bacillus thuringiensis var. israelensis (Bti) e em manejos mecânicos não só removendo os imaturos (ovos, larvas e pupas) por meio de escovação de vertedouros, mas também pela retirada de substratos naturais e antrópicos do leito. A densidade larvária média inicial, antes da aplicação de Bti no leito do riacho $(75 \mathrm{~m})$ e no último vertedouro, verificada em substratos antrópicos fitilhos (área $13.500 \mathrm{~cm}^{2}$ ), foi de 6,7 e 11,5 larvas $/ \mathrm{cm}^{2}$, respectivamente. Nestes habitats, o controle integrado com Bti de 1,77 a 2,09 mg/litro do ingrediente ativo, suplementado com manejos mecânicos, monitorado em substratos fitilhos (área $20.250 \mathrm{~cm}^{2}$ ), resultou em redução larvar de $72,61 \%$ a $99,97 \%$ e de $74,91 \%$ a $99,45 \%$, respectivamente, nas vazões de 0,39 a 0,45 e de 0,38 a $0,43 \mathrm{~m}^{3} / \mathrm{min}$. No primeiro vertedouro (área $5.110 \mathrm{~cm}^{2}$ ), porém, só com manejos mecânicos, atingiu-se a redução larvária de $53,81 \%$ a $99,59 \%$. O controle efetuado reduziu as picadas hematófagas ao nível esperado, surtindo o efeito positivo almejado.

Palavras-Chave. Controles Bti e mecânico; riacho; Simuliidae; vertedouros piscicultura.

Bactérias por natureza patogênicas para os insetos têm sido utilizadas há muitos anos como bioinseticidas na área agrícola e no controle de insetos vetores de patógenos.

A luta contra vetores de organismos nocivos e contra pragas hematófagas trava-se no mundo inteiro. O mercado mundial de inseticidas chega a gastar de 6 a 8 bilhões de dólares anuais para controlar diversos vetores de organismos patogênicos de doenças tropicais e para controlar as pragas na agricultura. A utilização atual de biopesticidas mal chega a $2 \%$ ou $2,5 \%$ deste total. No mundo todo, a cada ano, cerca de um bilhão de pessoas são acometidas por doenças graves causadas por organismos patogênicos veiculados por insetos vetores. A partir de 1980, graças aos esforços da Organização Mundial da Saúde conjugados a outros organismos 
internacionais e numerosos laboratórios de pesquisa, têm sido desenvolvidos programas internacionais para a utilização de Bacillus thuringiensis sorotipo israelensis (Bti) contra os insetos veiculadores de organismos nocivos. Os principais alvos são os dípteros de famílias Culicidae (mosquitos) e Simuliidae (borrachudos). O desenvolvimento da biologia molecular a partir da década de 1980 permitiu melhorar geneticamente o desempenho desta bactéria. Conseguiramse aperfeiçoamentos, sobre os quais trabalharam numerosos laboratórios no mundo e que ainda contribuirão decisivamente num futuro próximo na luta biológica contra os insetos. Bacillus thuringiensis é ativo contra insetos graças a uma inclusão cristalina (ou "cristal") composta de proteínas inseticidas, as delta-endotoxinas, codificadas pelos genes Cry. Uma centena destes genes têm sido clonados em seqüência. Estes produzem as $\delta$-endotoxinas muito diversificadas, cujos espectros de atividade variam de acordo com a raiz de Bt. A utilização desta $\delta$-endotoxina na luta biológica tem limitações. A duração de sua atividade na natureza é mais fraca que a dos inseticidas químicos. Dependendo de condições climáticas, as radiações ultravioletas sobre cristais tornam-na inativa e as chuvas provocam lavagens do produto bacteriano. Acrescente-se a isto que uma larga utilização de Bt com altas dosagens pode resultar em resistência adquirida de insetos às $\delta$-endotoxinas (Lecadet \& Rapoport 1997; Glare \& O' Callaghan 1998).

Biolarvicidas à base de Bacillus thuringiensis são empregados mundialmente em larga escala por suas qualidades de não poluir o ambiente, de preservar a maioria da fauna associada, de não ser tóxico aos humanos nem aos animais e de não ter sido observado, até o momento, o surgimento de espécies resistentes ao produto. A bactéria foi primeiramente isolada em 1902 por Ishiwata no Japão (LECADET \& RAPOPORT 1997; JeAn-François \& Nielsen-LeRoux 2000).

Atualmente, existem muitas formulações baseadas em Bacillus thuringiensis (Bt) dos sorotipos Bacillus thuringiensis aizawai, Bacillus thuringiensis israelensis, Bacillus thuringiensis kurstaki e Bacillus thuringiensis tenebrionis, todos recomendados para combater uma série relativamente grande de insetos das ordens Coleoptera, Diptera, Hemiptera e Lepidoptera (Glare \& O’ Callaghan 1998; Joung \& CôTÉ 2000).

O uso destes biolarvicidas, em relação aos demais inseticidas químicos, apresenta certas vantagens, entre elas a de não persistirem no ambiente por muito tempo após a sua aplicação. São produtos altamente seletivos, não fitotóxicos, suas formulações geralmente têm boa resistência às condições adversas e são inócuos a abelhas, a não ser em altas doses (Glare \& O' Callaghan 1998).

Goldberg \& Margalit (apud Glare \& O' Callaghan 1998), em 1976, em Israel, isolaram uma nova subespécie de Bt a partir de amostras de solo. Mais tarde, a subespécie foi identificada e denominada Bacillus thuringiensis israelensis (Bti), sorotipo H-14 (de Barjac, 1978). Este sorotipo tem sido considerado específico no combate a espécies de Culicidae e
Simuliidae. Outros grupos de dípteros, como Chironomidae e Tipulidae, por exemplo, demonstram certa susceptibilidade a este biolarvicida.

O desenvolvimento de resistência ao Bti ainda não foi observado, provavelmente, graças ao complexo do princípio ativo, a $\delta$-endotoxina, de uma linhagem não esporogônica de Bacillus thuringiensis $\mathrm{H}-14$ contida em um cristal protéico da bactéria (corpo para-esporal), insolúvel em água e em solventes orgânicos. Para ser efetivo, deve ser ingerido e o cristal solubilizado em meio alcalino entérico. As células da camada epitelial do intestino médio de larvas por ação da $\delta$-endotoxina perdem a integridade, rompendo-se e as larvas param de se alimentar, provocando a morte por inanição ou septicemia. $\mathrm{Na}$ maioria das vezes, a morte ocorre em menos de 24 horas (GLARE \& O`Callaghan 1998; Joung \& Côté 2000; Jean-François \& NieLSEN-LeRoux 2000).

O controle de simulídeos está sendo amplamente utilizado no mundo todo devido ao interesse em saúde pública e para prevenir perdas econômicas em agropecuária, tanto em áreas rurais como em regiões metropolitanas. Impactos econômicos negativos e reações alérgicas por picadas de borrachudos ocorrem também em áreas turísticas e rurais que agravam o bem-estar de todos. No Brasil, são poucos os trabalhos relacionados ao controle com Bti. Rio Grande do Sul foi o primeiro estado a trabalhar com este biolarvicida (RUAS Neto et al. 1984; Ruas Neto et al. 1985; Souza et al. 1994). São Paulo também conta com alguns trabalhos (ARAúJo-CoutinHo \& LaCey 1990; AndRade \& CASTello Branco 1991). No Paraná, despontam Lozover et al. (1992) e CUNHA \& BAssi (1997).

A exemplo disto, na área do presente estudo, houve excessiva infestação de simulídeos a ponto de prejudicar a convivência habitual e o próprio sucesso do empreendimento. Com meta de ampliar os conhecimentos sobre a ocorrência de espécies que se comportam como praga hematófaga, a presente investigação propôs-se efetuar a identificação e frequiência das espécies de Simulium que colonizaram os substratos naturais e antrópicos no leito do riacho e nas lajes dos vertedouros de açudes de piscicultura, e avaliar a eficiência do controle integrado pela aplicação de Bacillus thuringiensis israelensis Teknar $^{\circledR}$ em conjunto com os manejos mecânicos, a fim de reduzir o impacto negativo causado por estes hematófagos. E ainda, com os dados advindos do controle integrado, sugerir estratégias para a comunidade-alvo para manter sob controle a simuliofauna na área em questão.

\section{MATERIALEMÉTODOS}

O local desta investigação situa-se no município de Almirante Tamandaré, parte da Região Metropolitana de Curitiba, a $17 \mathrm{~km}$ ao norte da Capital paranaense, com extensão

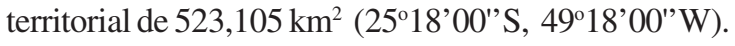

O clima caracteriza-se como subtropical úmido mesotérmico, com verões frescos e ocorrência de geadas severas e freqüentes no inverno, sem estação seca. A média de temperatura nos meses mais quentes é inferior a $22^{\circ} \mathrm{Ce}$, nos 
meses mais frios, a $18^{\circ} \mathrm{C}$ (FerReIRA 1996). As precipitações pluviométricas permanecem regulares todos os meses do ano.

O relevo apresenta uma paisagem suavemente ondulada, onde há formação Guabirotuba ou um relevo abrupto com predominância de rochas Pré-Cambrianas. A altitude situa-se em torno de 900 m (SuReHMA 1986). A vegetação, basicamente, compõe-se de mata pluvial tropical-subtropical, de campos e de florestas caducifólias subtropicais com presença de pinheiro, Araucaria angustifolia (Bertoloni) O. Kuntze (Araucariaceae) e bracatinga, Mimosa Linnaeus (Mimosaceae), constituindo cobertura vegetal pouco significativa.

O Riacho dos Padres, afluente do Rio Tanguá, que integra a Bacia do Rio Barigüi, difere de outros rios. O leito é reduzido, de pouca profundidade, muito irregular com pequenos empoçamentos, bifurcações e com muita matéria orgânica em decomposição em floculação resultante da ração de peixes.

Já em seu percurso inicial, o Riacho dos Padres sofreu muita modificação antrópica pela construção de tanques de piscicultura, cinco dos quais na Chácara Evíssima. Cada tanque dispõe de vertedouro para a entrada e saída de água. A laje do vertedouro, em desnível, de cimento irregularmente acabado (não alisado) propicia ambiente ideal à procriação de simulídeos por produzir alto teor de oxigênio dissolvido na água. Além disso, a vegetação aquática nas margens do riacho ou parcialmente submersa constitui ótimo substrato para simulídeos imaturos.

Além dos nativos, como lambari, Astyanax Baird \& Girard, 1854 (Characidae) e acará, Geophagus Heckel, 1840 e Cichlasoma Swainson, 1839 (Cichlidae), povoam os açudes de piscicultura os peixes introduzidos, como tilápias, Oreochromis Gunther, 1889 (Cichlidae) e carpas, Cyprinus Linnaeus, 1758 (Cyprinidae), destinados ao consumo humano.

O criadouro de simulídeos onde se desenvolveu a presente pesquisa na Chácara Evíssima está a cerca de mil metros à jusante da nascente do Riacho dos Padres em Lamenha Grande. Nessa área, continuamente permanecem muitas pessoas e são mantidos animais de grande e pequeno portes. A área não foi escolhida aleatoriamente. O trabalho de pesquisa foi desenvolvido por solicitação do proprietário para viabilizar o controle de insetos a fim de reduzir a praga hematófaga com o intuito de amenizar suas picadas, viabilizando a permanência e o lazer de humanos na chácara.

A identificação das espécies de Simulium baseou-se nas características morfológicas de pupas e adultos obtidos em laboratório, seguindo CoSCARÓN (1991) e STRIEDER et al. (1992).

A fauna associada aos substratos de simulídeos imaturos foi identificada com auxílio dos trabalhos de STEHr (1987 e 1991) e de Needham \& NeEdHam (1962).

Na propriedade Evíssima, o Riacho dos Padres percorre uma extensão de aproximadamente 330 metros. Os cinco tanques construídos na propriedade ocupam uma extensão de mais ou menos 210 metros de seu leito. Depois disso, entra na propriedade vizinha e segue o seu curso sem sofrer modificação alguma.

Em intensa infestação de borrachudos, como no presente caso, em que os insetos molestantes, causam transtorno à convivência habitual humana, inviabilizam o lazer e o sossego de animais e até depreciam os objetivos da microempresa, só resta o controle integrado para conseguir ação sinérgica. Esta foi a justificativa premente do imediato início do controle a fim de amenizar o problema surgido da excessiva proliferação de simulídeos.

Tipos de controle executado na Chácara Evíssima. Estabeleceu-se providenciar o controle de simulídeos, utilizando dois métodos: por manejos mecânicos e por controle integrado.

O manejo mecânico consistiu na remoção de imaturos (ovos, larvas e pupas) com todos os tipos de substratos - vegetais, galhos, folhas caídas e represadas, plantas aquáticas e semiáquaticas, e artefatos de lixo doméstico acumulados ao longo do leito do riacho. Para a remoção de imaturos das lajes de vertedouro, utilizou-se a técnica de escovar as lajes e coar, através de pano de nylon, toda a água com imaturos desprendidos.

O método integrado abrangia, além de manejos mecânicos, a exposição de larvas ao biolarvicida (Bti), diluído à alíquota de $50 \mathrm{~mL}$ em três litros de água e aplicado em locais preestabelecidos durante um minuto com um regador dotado de chuveirinho. Antes de aplicar o larvicida, computou-se o número de larvas em alguns fitilhos retirados dos habitats. Decorridas 48 horas da aplicação do formulado (Bti), procedeuse à coleta de larvas, em fitilhos, para acompanhar o resultado reducional. Em seguida, efetuou-se o controle com manejos mecânicos.

Avaliação da população larvar por substratos artificiais fitilhos. Em áreas predeterminadas para o controle integrado, as densidades larvares iniciais foram estimadas pela colonização de larvas em segmentos de fitilhos $(150 \times 0,5 \mathrm{~cm})$ colocados no primeiro segmento do leito do riacho $(75 \mathrm{~m})$ e na laje do vertedouro do último tanque. Utilizaram-se 45 fragmentos de fitilhos no segmento do riacho e outros tantos na laje do último vertedouro. Computando ambos os lados destes fragmentos, obteve-se uma área de $13.500 \mathrm{~cm}^{2}$ para colher dados iniciais sobre a densidade larvar média antes do tratamento. Para o monitoramento das subseqüentes nove aplicações de Bti, foram utilizados outros 135 fitilhos nas mesmas dimensões em cada um dos habitats tratados, do que resultou uma área de $20.250 \mathrm{~cm}^{2}$ por criadouro em questão no controle integrado. À retirada de fitilhos sucederam os manejos mecânicos nos dois criadouros. Do leito do riacho foram removidos os substratos naturais e artificiais, e na laje do vertedouro procedeu-se à escovação. Depois de cada operação, os fitilhos removidos foram substituídos por novos nas mesmas dimensões e nos mesmos locais. Nas reaplicações de Bti, o efeito letal larvário foi monitorado em substratos fitilhos tanto no leito do riacho como na laje do vertedouro, com o objetivo de confrontar os dados de antes da aplicação com os de 48 horas após. Nestes habitats, foram realizados nove controles 
integrados seqüenciais, iniciados em 28 de fevereiro de $2002 \mathrm{e}$ continuados pelos seis meses até 23 de agosto do mesmo ano.

Utilizou-se o produto Teknar ${ }^{\circledast}$ (Bti sorotipo H-14) da Zeneca do Brasil Ltda, à base de uma linhagem oligoesporogênica. As reaplicações do biolarvicida ocorreram em intervalos de aproximadamente 15 dias em locais preestabelecidos.

Disposição dos tanques e trechos livres do riacho na área trabalhada. Os cinco tanques da Chácara Evíssima, conectados entre si por tubulações de cimento e enfileirados, acompanham o declive do terreno. O primeiro tanque recebe a água da propriedade vizinha por um vertedouro de laje de cimento nas dimensões de 140 x $36,5 \mathrm{~cm}$ (área de $5.110 \mathrm{~cm}^{2}$ ). Nesta primeira laje, foi efetuado o controle de simulídeos unicamente por manejos mecânicos. Foram oito manejos mecânicos que somaram um total de $40.880 \mathrm{~cm}^{2}$ de área avaliada. Este trabalho foi iniciado em 15 de abril de 2002 e estendeu-se até 08 de agosto do mesmo ano. As larvas foram contadas para a estimativa da densidade inicial e para conferir, posteriormente, o índice reducional nos oito manejos seqüenciais, a fim de comparar estes dados com os nove monitoramentos seqüenciais de controle integrado.

Nas tubulações entre o segundo, terceiro e o quarto tanques, pela ordem, foi executado somente o controle por ação mecânica sem contagem de larvas.

Depois do quarto tanque, existe um segmento do riacho de curso livre numa extensão de 75 metros, como também depois do quinto, outro trecho do mesmo riacho também em curso livre de 45 metros. A saída da água do quinto tanque escoa por um vertedouro de laje de cimento de fundo irregular com dimensões de 1.048 x $107 \mathrm{~cm}$. Nestes dois trechos livres do riacho $(75 \mathrm{~m} \mathrm{e} 45 \mathrm{~m}$ ) e na laje do último vertedouro, o controle de simulídeos foi integrado (Bti e manejos mecânicos) com monitoramento de contagem de larvas para conferir a densidade larvária inicial e o seu índice reducional após as aplicações do formulado Bti. Convêm lembrar que o controle integrado na laje do último vertedouro incluiu o trecho do riacho de 45 metros.

A vazão da água no riacho com leito parcialmente pedregoso e lamacento e na laje de cimento do vertedouro foi obtida pela fórmula $\mathrm{Q}=\mathrm{Lm} \times \mathrm{Pm} \times$ a $\times \mathrm{C} \times \mathrm{Tm}^{-1}$ (onde, $\mathrm{Q}=$ vazão $\mathrm{em} \mathrm{m}^{3} / \mathrm{min}$.; $\mathrm{Lm}=$ largura média do riacho em metros; $\mathrm{Pm}=$ profundidade média em metros; $\mathrm{a}=$ valor constante do fundobarro, areia, etc $=0.90$ e pedras, cimento $=0.85 ; \mathrm{C}=$ comprimento do trecho do riacho avaliado de $10 \mathrm{~m}$.; $\mathrm{Tm}=$ tempo médio em minutos que uma bola de pingue-pongue com 1/3 de água como lastro, levou a percorrer o comprimento C).

\section{RESULTADOS EDISCUSSÃO}

A composição faunística submetida ao controle integrado e ao manejo mecânico no Riacho dos Padres, identificada conforme frequiências percentuais, constou de seguintes espécies: Simulium (Inaequalium) inaequale Peterson \&
Shannon, $1927(55,24 \%)$ do total de 24.021 pupas; $S$. (Ectemnaspis) perflavum Rouband, 1906 (16,81\%); S. (Chirostilbia) pertinax Kollar, 1932 (13,93\%); S. (Thyrsopelma) orbitale Lutz, 1910 (8,03\%); S. (Inaequalium) subnigrum Lutz, 1910 (4,92\%); S. (Chirostilbia) distinctum Lutz, 1910 (1,03\%) e S. (Psaroniocompsa) incrustatum Lutz, $1910(0,04 \%)$. As três primeiras espécies somaram $85,98 \%$ do total analisado, com a peculiaridade de se destacarem por frequiência constante em todos os tipos de substratos. As outras quatro contribuíram somente com $14,02 \%$ e colonizaram os substratos em número reduzido de exemplares e em frequiência bastante irregular.

Densidades iniciais e índices reducionais por ação de manejos mecânicos. Antes de proceder ao manejo mecânico na laje do primeiro vertedouro, observou-se que este substrato tinha sido colonizado tão abundantemente que havia camadas superpostas de imaturos (pupas, larvas e ovos). No conjunto, houve predominância de larvas, colonizando inclusive os casulos de pupas e as laterais da laje. Neste habitat, a densidade larvária média inicial (15.IV.2002), foi de 10,3 larvas $/ \mathrm{cm}^{2}$, cabendo às larvas de $3^{\circ}$ aos últimos ínstares 9,61 larvas $/ \mathrm{cm}^{2} \mathrm{e}$ 0,66 larvas $/ \mathrm{cm}^{2}$ às de $1^{\circ}$ e $2^{\circ}$ ínstares. Do segundo ao oitavo manejos, (02.V.2002 a 08.VIII.2002), conseguiu-se reduções seqüenciais de $53,81 \%, 98,34 \%, 87,52 \%, 97,88 \%, 97,37 \%$, $99,46 \%$ e $99,59 \%$, respectivamente. Já a partir do terceiro manejo mecânico, houve uma drástica queda no número de larvas. Assim, pôde-se conferir que, na laje do vertedouro em questão, só a ação de manejos mecânicos aplicados produziu o efeito reducional desejado e esperado. Os manejos mecânicos, além de larvas, removeram todas as formas de imaturos, assim frustraram o desenvolvimento de miríades de adultos hematófagos pela limpeza geral que por sua natureza promoveram.

Densidades larvares iniciais e índices reducionais por ação do controle integrado. Antes de dar início ao controle integrado, tanto no primeiro segmento do riacho $(75 \mathrm{~m})$ como na laje do último vertedouro, as densidades larvares acusaram índices elevados. No primeiro segmento do riacho, a densidade inicial acusou, em média, 6,7 larvas $/ \mathrm{cm}^{2}$, sendo 3,5 larvas $/ \mathrm{cm}^{2}$ as de $1^{\circ}$ e $2^{\circ}$ ínstares e 3,2 larvas $/ \mathrm{cm}^{2}$ as de $3^{\circ}$ aos últimos. Os imaturos proliferaram em água de velocidades variadas entre 0,18 e $0,19 \mathrm{~m} / \mathrm{seg}$. Na laje do último vertedouro, a densidade larvária inicial foi a mais alta entre os três habitats trabalhados, acusando 11,5 larvas $/ \mathrm{cm}^{2}$, com 6,71 larvas $/ \mathrm{cm}^{2}$ de $1^{\circ}$ e $2^{\circ}$ ínstares e de 4,82 larvas $/ \mathrm{cm}^{2}$ de $3^{\circ}$ ínstar em diante. A colonização de imaturos, neste criadouro, deu-se em água de velocidades entre 0,49 e $0,50 \mathrm{~m} / \mathrm{seg}$. Nestes dois últimos habitats, a colonização predominante por larvas foi nos ínstares iniciais, contrapondo-se aos resultados obtidos na laje do primeiro vertedouro, em que a colonização predominante foi por larvas de $3^{\circ}$ ínstares em diante. Estes dados serviram de ponto de partida para as aplicações do biolarvicida.

Os índices reducionais de larvas, no primeiro segmento 
do riacho $(75 \mathrm{~m})$, da primeira à nona aplicações seqüenciais foram de $89,03 \%, 97,85 \%, 88,81 \%, 99,97 \%, 72,61 \%, 72,48 \%$, $91,20 \%, 95,20$ e $91,88 \%$, nas concentrações do formulado entre 1,77 e $2,03 \mathrm{mg} /$ litro do ingrediente ativo. Neste habitat, a vazão da água variou de 0,39 a $0,45 \mathrm{~m}^{3} / \mathrm{min}$. Pode ser considerado, portanto, de bom desempenho funcional o resultado conseguido com a ação de Bti reforçado com os manejos mecânicos. Lozover et al. (1992), no Rio Dom Rodrigo, Região Metropolitana de Curitiba, Paraná, também testaram o controle de simulídeos com a remoção física de imaturos (ovos, larvas e pupas), no leito do rio e em lajes de vertedouro unicamente com manejo mecânico com ótimos resultados. O manejo mecânico, comprovadamente, constitui uma técnica econômica, eficiente, de fácil execução, sem causar impacto negativo ao meio ambiente, ao homem nem aos animais domésticos. Consiste na remoção física de todas as fases imaturas, enquanto a ação letal do biopesticida Bti só elimina as larvas em algumas horas após a ingestão.

Em termos de efeito redutor larval, na laje do último vertedouro durante o controle integrado, constatou-se considerável diminuição da simuliofauna. Os percentuais reducionais seqüenciais da primeira à nona aplicações foram $91,62 \%, 96,07 \%, 86,36 \%, 99,45 \%, 74,91 \%, 76,88 \%, 90,44 \%$, 95,06\%, 89,21\% nas aplicações com concentrações de ingrediente ativo de 1,80 a $2,09 \mathrm{mg} / \mathrm{litro}$. A vazão da água, neste habitat, oscilou de 0,38 a $0,44 \mathrm{~m}^{3} / \mathrm{min}$. Houve, portanto, ótimo desempenho funcional na ação do controle integrado neste habitat.

Resumindo, nos três habitats trabalhados, as oviposições foram presentes durante todo o processo de tratamento. As reinfestações continuadas de simulídeos depois de cada aplicação do controle integrado provocaram a predominância de larvas de $1^{\circ} \mathrm{e} 2^{\circ}$ ínstares às de $3^{\circ}$ aos últimos. Não obstante, o número reduzido de larvas de $3^{\circ}$ aos últimos ínstares caracteriza um bom resultado por impedir imediata formação de adultos.

É interessante ressaltar que o controle integrado em ambos os habitats - no leito do riacho e na laje do último vertedouro - resultou em comportamento similar. Como resultado, as colonizações populacionais de larvas predominaram nos ínstares iniciais nestes habitats, visto que os ovos e as pupas permaneceram intactos nas aplicações de Bti, mas removidos em controle mecânico junto com os substratos e por escovação. Convém salientar que, em relativamente pouco tempo, o controle integrado determinou resultados imediatos e satisfatórios.

Finalmente, é bom frisar que, nos controles inicias em ambas as lajes dos vertedouros da Chácara Evíssima, a proliferação de simulídeos ocorreu com tal exuberância que os imaturos (ovos, larvas e pupas) formaram uma camada espessa depositada nos substratos. Mesmo assim, estas implicações não interferiram na eficiência das ações de manejo mecânico e no controle com Bti ao longo das aplicações, fato confirmado pela redução larvar na laje do vertedouro e no leito do riacho.
Outros pesquisadores, como Melo et al. (1984), MardinI (2000) e RuAs Neto et al. (1984) recomendam a integração de métodos, a educação ambiental das comunidades envolvidas e a preservação ambiental pela eficiência indefectível no controle de borrachudos.

O controle da fauna de simulídeos promovido no Riacho dos Padres, trazendo benefícios positivos, não só melhorou a qualidade de vida de residentes e visitantes da área, como também lhes abriu novos horizontes. Demonstrou técnicas acessíveis e eficazes para se livrarem dos indesejados insetos sem necessidade de gastos excessivos com o Bti. Enfatizou a necessidade de eles mesmos, por iniciativa própria, assumirem o empreendimento pelo menos a cada 15 dias a fim de que o bem-estar não deteriore. Foi o que o presente trabalho pretendeu demonstrar. E conseguiu. Dez meses depois de concluído o controle, em visita, constatou-se que a lição foi assimilada e aplicada integralmente. Livres de borrachudos hematófagos, em termos, os usuários da chácara usufruem prazerosamente o lazer nos finais de semana.

$\mathrm{Na}$ verdade, nenhum método de combate aos vetores e pragas hematófagas será capaz de satisfazer plenamente as necessidades exigidas. Não há como erradicar a praga totalmente. É importante, porém, adotar um conjunto de critérios e métodos para alcançar um desempenho integral (HАвІB 1989), direcionados para não criar problemas que agridam ou comprometam a saúde humana com a veiculação de organismos patogênicos.

No presente estudo confirmou-se que foram adequados os manejos mecânicos e a concentração de doses de Bti aplicadas em locais preestabelecidos, embora no início de cada tratamento subseqüiente sempre tenha havido imaturos colonizando. Se tivessem sido utilizadas doses mais concentradas de Bti, poder-se-ia ter conseguido mais rápida e drástica baixa de imaturos. Preferiu-se, porém, aplicar doses moderadas para não expor as larvas à delta-endotoxina por muito tempo.

Segundo Glare \& O’ Callaghan (1998), este biopesticida não causa danos a pessoas, animais, peixes ou outros insetos associados ou quaisquer outros organismos não-alvos. Merece ser destacado que, durante a aplicação de Bti no criadouro estudado, a fauna não-alvo associada aos substratos de simulídeos parece não ter sido afetada, pois se fez presente em todas as amostras monitoradas. Os principais grupos encontrados foram Platyhelminthes (Turbelaria), Annelida (Hirudinea), Gastropoda (Biomphalaria e Lymnaea), Acari (Hydracarina), Diplopoda, Colembola, Plecoptera (Grypopterydae), Coleoptera (Hydrophilidae), Diptera (Tipulidae, Ceratopogonidae, Chironomidae e Empididae), Trichoptera (Hydropsychidae) e Hymenoptera (Plastygasteridae).

\section{CONCLUSÕES}

Sete espécies de Simulium presentes no leito do Riacho dos Padres e nas lajes de vertedouros de piscicultura foram 
submetidas ao controle. Simulium. inaequale $(55,24 \%), \mathrm{S}$. perflavum $(16,81 \%)$ e $S$. pertinax $(13,93 \%)$ foram de maior freqüência. As outras espécies, $S$. orbitale $(8,03 \%), S$. subnigrum (4,92\%), S. distinctum (1,03\%) e $S$. incrustatum $(0,04 \%)$, ao contrário, colonizaram os mesmos substratos, porém, proliferaram com freqüências reduzidíssimas e inconstantes.

Em ambas as lajes dos vertedouros trabalhados, o de controle integrado e o de manejo mecânico, no inicio foi constatada elevada colonização por ovos e larvas, um destaque peculiar neste tipo de criadouro ao longo da investigação na área da Chácara Evíssima.

O controle integrado (Bti e manejo mecânico), aplicado no leito do riacho de $75 \mathrm{~m}$ e na laje do último vertedouro (112.136 $\mathrm{cm}^{2}$ ), concretizou os esforços para reduzir as populações de simulídeos hematófagos ao nível aceitável, embora não tenha conseguido erradicá-los. Conseguiu-se a meta, portanto, de proporcionar à comunidade-alvo a convivência e o bem-estar geral almejados.

O índice reducional médio de larvas no controle integrado foi de $88,83 \%$, em ambos os habitats - no segmento do leito e na laje do vertedouro, cabendo a média de $88,78 \%$ ao primeiro habitat e $88,89 \%$, ao segundo. Já o controle executado só com manejos mecânicos na laje do primeiro vertedouro, a partir do segundo controle alcançou uma redução média de 90,57\%, levando pequena vantagem em relação ao controle integrado. No presente caso, o percentual corrobora a maior vantagem em combater os borrachudos por manejos mecânicos em laje de vertedouro. Esta técnica com menos gastos elimina não só as larvas, mas também os ovos e as pupas, frustrando o surgimento imediato de adultos.

Recomendações. No Sul do Brasil, como não há veiculação de organismos parasitários por simulídeos, a escolha do método para combater esta praga hematófaga, sempre que possível, caberia perfeitamente a manejos mecânicos. Os manejos mecânicos deveriam constituir o método preferencial pela fácil e econômica execução e pela certeza de resultado mais rápido. Estas vantagens deveriam incentivar a comunidade a interessar-se pela técnica e a adotá-la. Promover uma educação ambiental e hidrográfica em comunidades com proliferação exagerada de simulídeos e estimulá-las a resolverem suas necessidades por iniciativa e recursos próprios - eis a recomendação final. Para ser duradoura, a melhor qualidade de vida inclui constante empenho, zelo pela higiene do meio e adoção de medidas de reequilíbrio ambiental.

Agradecimentos. À Prefeitura Municipal de Curitiba pelo fornecimento do produto biolarvicida (Bti) aliado ao programa de Controle de Vetores e pelo apoio logístico dispensado durante a execução deste trabalho. Ao Engenheiro Agrônomo Dr. Hugo Reis Vital, da Empresa Bioagro na qualidade de expert em uso e aplicação de Bti, pela cooperação e adequação da dose de Bti para este trabalho, desenvolvido em conjunto ao Programa de Controle de Vetores do Município de Curitiba, Paraná, Brasil.

\section{REFERÊNCIAS}

Andrade, C. F. S. \& A. Castelo Branco JR. 1991. Susceptibilidade de populações de Simulium (Chirostilbia) pertinax Kollar, 1832 (Culicomorpha, Simuliidae) ao temephos e a um formulado à base de Bacillus thuringiensis var. israelensis. Revista de Saúde Pública 25(5): 367-370.

Araújo-Coutinho, C. J. P. C. \& L. A. Lacey. 1990. Controle de simulídeos com concentrado emulsionável de Bacillus thuringiensis. Boletin de la Oficina Sanitaria Panamericano 108(3): 213-219.

Coscarón, S. 1991. Fauna de Agua dulce de la Argentina, Simuliidae. Fascículo 2. Buenos Aires, Fundación para la Educación, la Ciencia y la Cultura (FECIC), 304 p.

Cunha, M. C. I. DA \& R. M. A. DE Bassi. 1997. Ensayo com Bacillus thuringiensis var. israelensis (Diptera, Simuliidae) en el rio São João, Paraná, Brasil. Acta Biológica Paranaense 26(1-4): 9-16.

Ferreira, J. C. V. 1996. O Paraná e seus Municípios. Maringá, Edição Memória Brasileira, 728 p.

Glare, T. R. \& N. M. O' Callaghan. 1998. Environmental and Health Impacts of Bacillus thuringiensis israelensis. Report for the Ministry of Health, Grasslands, New Zealand. Division, AgResearch, Lincoln, $58 \mathrm{p}$.

НАвıв, M. E. M. 1989. Uma Política para o Controle de Borrachudos no Brasil. Seminário Sobre Insetos e Ácaros. Anais da Sociedade Entomológica do Brasil 3: 99-102.

Jean-François, C. \& C. Nielsen-LeRoux. 2000. Mosquitocidal Bacterial Toxins: Diversity Mode of Action and Resistance Phenomena. Memórias do Instituto Oswaldo Cruz 95(1): 202-206.

Joung, K. B. \& J. C. Côté. 2000. A Review of the Environmental Impacts of the Microbial Insecticide Bacillus thuringiensis. Tecnical Bulletin n ${ }^{\circ} 29$, Québec, 16 p.

LECADET, M. \& G. RAPOPORT. 1997. La lutte bactériologique contre les insectes. Disponível em: <http://www.pasteur.fr/actu/presse/ com/dossiers/lutbio.html> Acesso em: 11.abr.2003.

Lozovei, A. L.; M. C. I. Da Cunha \& V. L. R. De Oliveira. 1992. Controle físico de Simulídeos (Diptera, Simuliidae) em vertedouros de açudes de piscicultura e no leito do Rio Don Rodrigo, Campo Largo, Paraná, Brasil. Arquivos de Biologia e Tecnologia 35(4): 679-684.

Mardini, L. B. L. F. 2000. Programa de Controle de Simulium sp. no Rio Grande do Sul. Vetores \& Pragas 2(6): 23-25.

Melo, J. L. B. DE; M. A. T. SouZA \& S. J. B. DE Oliveira. 1984. Considerações gerais sobre o método de controle mecânico dos simulídeos. Boletim de Saúde 11(12): 12-16.

Needham, J. G. \& P. R. Needham. 1962. A guide to the study of FreshWater Biology. San Francisco, Holden-Day Inc., 107 p.

Ruas Neto, A. L.; E. P. De Caldas \& M. A. T. Souza. 1984. Programa Estadual de Controle de Borrachudos: controle de simulídeos no Rio Grande do Sul, aspectos gerais. Boletim de Saúde 11(2): 4-7.

Ruas Neto, A. L.; M. A. T. Souza; S. Severino; J. L. B. De Melo; S. M. Silveira \& N. D. F. De Fortes. 1985. Controle integrado de Simulium (Chirostilbia) pertinax Kollar, 1832. 1. Utilização de Bacillus thuringiensis var. israelensis em três municípios do Rio Grande do Sul. Boletim de Saúde 12(2): 17-20.

Souza, M. A. T.; L. L. F. Mardini; E. C. Gomes \& G. L. Da Silveira. 1994. Evolução do Controle Biológico de Simulídeos através do Bacillus thuringiensis var. israelensis no Rio Grande do Sul, Brasil. Informe do Programa Estadual de Controle dos Simulídeos da Divisão de Zoonoses e Vetores da Secretaria de Saúde e Meio Ambiente, Rio Grande do Sul, 15 p.

Stehr, F. W. 1987. Immature Insectes, $1^{\text {st }}$ ed. Debuque, Kendall Hunt Publishing Company, 754 p.

Stehr, F. W. 1991. Immature Insectes. $2^{\text {nd }}$ ed. Debuque, Kendall Hunt Publishing Company, $975 \mathrm{p}$.

Strieder, M. N.; E. Corseuil \& V. Py-daniel. 1992. Espécies do gênero Simulium (Diptera, Simuliidae) ocorrentes no Rio Grande do Sul, Brasil, com chaves para sua identificação. Acta Biológica Leopoldensia 14(2): 53-74.

Surehma - Superintendência de Recursos Hídricos e Meio Ambiente. 1986. Núcleo de Estudos e Aproveitamento de Recursos Hídricos e Núcleo de Qualidade Ambiental. Estudo da Bacia Hidrológica do Rio Bariguii. Curitiba, 88 p. 